\title{
Understanding the consumer shopping experiences on Black Friday using critical incident technique \\ - Focused on the responses of university students in the United States -
}

\author{
Soo In Shim ${ }^{\dagger}$ \\ Dept. of Clothing \& Textiles, Chonbuk National University, Korea

\section{결정적 사건 기법을 이용한 소비자의 블랙 프라이데이 쇼핑 경험에 관한 연구 - 미국 대학생 소비자의 응답을 중심으로 -}

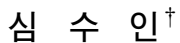 \\ 전북대학교 의류학과
}

\begin{abstract}
Black Friday, a biggest holiday shopping season in the United States, has been regarded as a great opportunity that fashion retailers can dramatically increase their sales. However, there has been a lack of attention to consumers' shopping experiences on Black Friday from the consumer perspectives. The objective of this study is to explore consumer shopping experiences on Black Friday, in terms of consumer responses toward the experiences, shopping values, and any possible factors influencing the experiences. The method of critical incident technique was used with 198 critical incidents extracted from 165 responses of university students in the United States. As results, the shopping experiences on Black Friday were categorized into positive vs. negative shopping experiences. After that, the positive and negative experiences were respectively divided into two common themes: utilitarian shopping value vs. hedonic shopping value. In addition to the common themes, 12 categories were also emerged. Among positive experiences, utilitarian shopping experiences includes two categories of off-price shopping and shopping for expensive products, whereas hedonic shopping experiences includes three categories of impulse buying, holiday atmosphere, and shopping for the latest or luxury brand products. Among negative experiences, utilitarian shopping experiences includes four categories of modest discounts, out of stock, time-consuming queues, and fatigue of holiday shopping, while hedonic shopping experiences includes three categories of crowded environments, compulsive buying, and poorly managed stores. In conclusion, it is notable that consumer can undergo negative as well as positive shopping experiences on Black Friday. Implications and suggestions are also discussed.
\end{abstract}

Keywords: Black Friday(블랙 프라이데이), shopping experiences(쇼핑 경험), hedonic value(쾌락적 가치), utilitarian value(실용적 가치), critical incident technique(결정적 사건 기법)

Received 7 April 2014, revised 23 April 2014, accepted 23 April 2014.

${ }^{\dagger}$ Corresponding author (sooinshim@gmail.com)

This is an Open Access article distributed under the terms of the Creative Commons Attribution Non-Commercial License (http://creativecommons.org/licenses/by-nc/3.0) which permits unrestricted non-commercial use, distribution, and reproduction in any medium, provided the original work is properly cited. 


\section{Introduction}

주말이나 공휴일, 휴가 기간은 소비자들이 쇼핑 을 위한 시간적 여유가 충분한 시기로, 유통업체는 이 시기 동안 최대한 많은 역량을 집중하여 성과를 창출하기 위해 노력한다. 특히, 한국의 설이나 추 석, 미국의 추수감사절이나 크리스마스 시즌 같은 연휴 기간은 소비자들이 소비가 대폭 늘어나 기업 의 매출이 급등할 뿐 아니라, 일시적으로 고용 창출 효과도 가져온다는 점에서 경제적으로 중요한 의미 를 갖는다. 블랙 프라이데이(Black Friday)는 미국 의 추수감사절(매년 11 월 넷째 주 목요일)의 다음 날인 11월 넷째 주 금요일로, 크리스마스와 더불어 가장 규모가 큰 쇼핑 시즌으로 꼽힌다. National Retail Federation(NRF)의 2013년 월별 매출 동향 자료에 의하면, 평달의 매출이 약 2 천 5 백억 달러인데 비 하여 블랙 프라이데이와 크리스마스가 속한 11월, 12 월의 매출은 3 천억 달러를 넘겨 다른 달의 매출 보다 두드러지게 증가한 경향을 보인다(NRF, 2014a). 이러한 연휴 기간의 전체 매출액 규모는 2009년 이 후 지속적인 증가세를 보여(NRF, 2014a), 소비자들 의 주요 쇼핑 시즌을 유통업체가 어떻게 활용하느 냐에 대한 중요성이 더욱 두드러진다. 특히, 의류 및 액세서리 같은 패션 제품군에서도 연휴 기간의 매 출이 전년도 대비 $4.7 \%$ 증가한 것으로 나타나(NRF, 2014b), 패션 유통업에서도 블랙 프라이데이 같은 쇼핑 시즌의 중요성이 더 강조된다.

블랙 프라이데이는 전통적으로 큰 폭의 가격할 인을 통해 소비자를 유인하고, 재고를 빠른 시간 내에 소진시킨다는 점에서 유통업계에 주는 의의 가 크다. 최근에는 블랙 프라이데이 행사 가격을 더 이른 시간부터 적용하거나 더 큰 폭의 할인가를 제시하는 등 유통업체들의 마케팅 프로모션 전략 이 적극적으로 전개되고 있다(Lennon, Johnson, \& Lee, 2011). 또한, 블랙 프라이데이 동안 거둘 수 있 는 비즈니스 성과를 높이기 위해 대중매체 역시 더 욱 적극적으로 활용되고 있다. 많은 매체들이 블랙 프라이데이를 앞두고, 각 유통업체별 블랙 프라이 데이 행사 가격이 제품 당 얼마인지, 언제부터 행 사 가격이 적용되는지, 소비자의 입장에서 큰 이득 을 취하기 위한 최적의 쇼핑 전략을 무엇인지 분석
하는 보도를 낸다(Carr, 2008).

이러한 유통업계와 매체의 노력은 비단 미국 시 장에만 해당되지는 않는다. 한국에서도 소비자들이 중간 수입상을 통하지 않고, 온라인 쇼핑을 통해 해 외 유통업체의 제품을 직접 구매하려는 비중이 점 차 늘어나고 있고, 이러한 해외 직접 구매 행동이 절정을 이루는 시기가 미국의 블랙 프라이데이 시 즌이다(Lee, 2014). 해외 직접 구매에 대한 국내 소 비자들의 관심 덕에 블랙 프라이데이는 이미 온라 인 유통업계의 대표 행사로 자리매김했고, 국내 온 라인 유통업체들도 유사 행사를 기획하여 이러한 소비자의 욕구에 대처하고 있다(Ahn, 2014). 오프 라인 유통업계에서도 블랙 프라이데이의 개념을 도 입하여 제한된 시간 내 파격적인 가격 할인 프로모 션을 제안하는 사례가 나타나고 있다. 최근 '한국 판 블랙 프라이데이' 행사를 개최하여 두 시간 만 에 매출 2억 원을 달성한 백화점은 동일 행사를 당 분간 지속하려는 움직임을 보이고 있다(Park, 2014; $\mathrm{Yu}, 2013)$. 나아가 정부 역시 소비를 촉진하기 위한 방안으로 블랙 프라이데이 같은 국가적 쇼핑 주간 을 신설하는 것을 검토하고 있다(Cho, 2014). 블랙 프라이데이에 대한 국내 소비자들의 관심 증가와 유사 행사를 적극 도입하려는 한국 유통업계와 정 부의 움직임을 고려해 볼 때, 블랙 프라이데이의 소비 행동에 관한 연구가 특정 국가에서만 활용 가 능하다고 보는 관점은 블랙 프라이데이가 주는 시 사점을 축소시킬 수 있다. 따라서 블랙 프라이데이 를 미국에 국한된 쇼핑 시즌으로 바라보기 보다는 제한 시간 내 파격적인 가격 할인을 진행하는 공인 된 대규모 프로모션 행사로 이해하는 것이 적절할 것이다.

그러나 블랙 프라이데이의 경제적 효과에 비해, 소비자가 느끼는 블랙 프라이데이 쇼핑 경험은 상 대적으로 주목을 받지 못했다. 소비자 경험은 소비 자의 만족을 증진시키고, 기업의 성과에 긍정적으 로 작용할 수 있기 때문에 그 중요성을 간과할 수 없다(Ballard, 2011). 또한, 소비자 경험은 브랜드 인 지, 브랜드 연상, 지각된 품질, 브랜드 충성에 모두 영향을 미치기 때문에, 브랜드 관리적 측면에서도 중요하다(Biedenbach \& Marell, 2010). 따라서 기 업은 소비자가 제품이나 서비스와 교감하는 모든 
접점에서 어떤 경험을 하는지 이해할 필요가 있다 (Grewal, Levy \& Kumar, 2009; Puccinelli et al., 2009). 이러한 소비자 경험의 중요성을 고려해볼 때, 소비자가 느끼는 블랙 프라이데이 쇼핑 경험에 대해 깊이 이해하고, 전반적인 쇼핑 경험에 영향을 미치는 요인이 무엇인지 밝힐 필요가 있다.

블랙 프라이데이의 쇼핑 경험에 대해 소비자의 입장에서 살펴본 선행연구는 양적으로 매우 부족 하다. Grewal, Roggeveen, Compeau and Levy (2012) 은 블랙 프라이데이에 유통업자들이 인기 있는 제 품을 파격적인 가격에 제공하는 이유로 기업 홍 보, 소비자의 매장 방문 촉진, 세일 외 제품의 매 출 증가를 꼽았으나, 이러한 결과는 유통업체의 입 장에서 얻을 수 있는 이점이고, 소비자의 쇼핑 경 험 자체에 대해서는 언급하지 않았다. 따라서 소비 자들이 유통업체의 의도대로 블랙 프라이데이의 이점을 실제로 인지하고 누리고 있는지에 대해서 는 알 수 없다. 또한, 블랙 프라이데이의 소비자 행 동에 초점을 맞춘 몇몇 선행연구들은 블랙 프라이 데이에 대한 소비자의 태도나 행동적 의도 간 관계 를 연구하거나(Swilley \& Goldsmith, 2013), 블랙 프라이데이에 나타나는 소비자의 행동을 유형화한 데 그친다(Jane Boyd \& Peters, 2011). Swilley and Goldsmith(2013)의 연구는 선행연구를 통해 반복적 으로 검증된 즐거움과 쇼핑 태도간의 관계를 블랙 프라이데이라는 특수한 상황에 적용시켜 검증했기 때문에, 선행연구에 틀을 제약된다는 양적 연구의 한계를 벗어나지 못한다. Jane Boyd and Peters(2011) 의 연구는 블랙 프라이데이의 소비자 행동을 질적 으로 분석하여 블랙 프라이데이 쇼핑의 특수한 현 상을 살펴본다는 데에 의의가 있으나, 결과가 다소 일반적이어서 소비자의 쇼핑 경험을 구체적인 수 준으로 분류할 수 있는 범주를 제시하지는 못했다.

이에 따라, 본 연구에서는 소비자의 블랙 프라이 데이 쇼핑 경험을 결정적 사건 기법을 활용해 질적 으로 분석하고, 블랙 프라이데이 쇼핑에 대한 소비 자의 반응, 추구 가치, 영향을 미치는 요인에 대해 탐색해 보고자 한다. 결정적 사건기법은 연구자가 인위적으로 설계한 틀이나 문항의 사용을 줄이고, 응답자의 관점과 언어를 최대한 존중하여 자료를 수집하기 때문에, 현상의 본질을 편견 없이 탐색하
기 적합한 질적 연구 방법이다. 또한, 인상적인 쇼 핑 경험을 체계적으로 분류하는 과정에서 긍정적 쇼핑 경험뿐 아니라, 부정적 쇼핑 경험도 살펴볼 수 있으며, 쇼핑 경험에 대한 두 가지 엇갈리는 반 응을 형성하는 요인이 무엇인지 다각적으로 탐색 할 수 있다. 블랙 프라이데이 쇼핑 경험 평가가 영 향을 미칠 수 있는 소수의 특정 사건들까지 간과하 지 않고 있는 그대로 살펴볼 수 있다는 점에서, 결 정적 사건기법은 본 연구의 목표를 달성하는 데 주 효할 것으로 보인다.

\section{Literature Review}

\section{Black Friday}

블랙 프라이데이라는 용어는, 유통업자들이 회 계 장부를 작성할 때 손실에 대해서는 붉은 잉크로, 이익에 대해서는 검은 잉크로 숫자를 기입하는 데 에서 비롯되었다. 블랙 프라이데이에 급격하게 늘 어나는 매출 덕에 유통업자들의 적자가 흑자로 전 환되는 일이 많았고, 회계 장부 역시 붉은색에서 검은색으로 바뀌었기 때문에, 이 날을 블랙 프라이 데이라고 부른 것이다(Jane Boyd \& Peters, 2011). 블랙 프라이데이는 미국의 국가 공휴일은 아니지 만, 가족 및 이웃 간 화합을 확인하는 큰 명절인 추 수감사절 다음 날이기 때문에 사회적 관행처럼 휴 일로 인식되어 왔으며, 블랙 프라이데이 이후 바로 주말이 이어지기 때문에 자연스레 연휴가 형성되 었다. 이러한 연휴 기간 동안 가족 단위로 쇼핑을 즐기려는 잠재 고객을 잡기 위해서 여러 유통업자 들이 대대적인 가격 할인을 진행하였다. 최근에는 더 많은 고객을 유인하기 위해 블랙 프라이데이 자 정 혹은 새벽부터 매장을 열고, 일정 시간 동안 추 가적인 할인율을 적용하거나, 몇몇 한정된 제품에 파격적인 할인가를 적용하는 유통업자들이 증가하 였다. 이에 따라 소비자들이 새벽부터 매장 앞에서 줄을 서서 매장이 열리기를 기다리는 진풍경이 종 종 연출되기도 하였다. Jane Boyd and Peters(2011) 는 이러한 블랙 프라이데이 만의 독특한 쇼핑 양상 을 보고, 유통업자들의 가격 할인 전술과 소비자들 의 절약 욕구가 어우러진 소비 의식(consumption ritual)이라고 규정하였다. 
블랙 프라이데이에 누릴 수 있는 엄청난 폭의 가 격 할인이 반드시 소비자의 긍정적인 쇼핑 경험으 로 이어진다고 할 수는 없다. Swilley and Goldsmith (2013)는 소비자들에게 연휴 기간의 쇼핑은 양날이 검이라고 표현하면서, 블랙 프라이데이의 쇼핑 경 험이 긍정적 혹은 부정적일 수 있다는 점을 시사하 였다. 지인에게 줄 선물을 고르는 즐거운 쇼핑이 될 수도 있지만, 누구에게 무엇을 얼마나 지출할지 결정하는 과정은 유쾌하지 않을 수도 있기 때문이 다. 블랙 프라이데이에 쇼핑 중인 소비자를 관찰한 Simpson, Taylor, Kathleen, O'Rourke and Shaw(2011) 의 연구에서는 매장이 영업을 시작했을 때 행복해 하고 흥분하는 등 긍정적인 반응을 보인 소비자가 많았지만, 비슷한 수준으로 피곤해 하거나 긴장하 거나 계획한 물건을 사지 못할까 걱정하는 등 부정 적 반응을 보인 소비자도 관찰된 것으로 나타났다. 이러한 결과를 고려하면 블랙 프라이데이의 쇼핑 경험이 반드시 긍정적인 경험이라고 보기 어려우 며, 유통업자들이 잠재 고객을 끌기 위해 사용한 유인책이 오히려 소비자들에게 부정적인 쇼핑 경 험을 줄 수도 있다는 점을 시사한다. 그러나 아직 까지 블랙 프라이데이의 쇼핑 경험에 대한 소비자 의 긍정적 및 부정적 반응을 체계적으로 탐색한 연 구는 수행되지 않았으며, 어떤 요인이 그러한 반응 이 이끌어내는지 구체적인 차원을 밝힌 연구도 부 족한 실정이다. 따라서 소비자의 블랙 프라이데이 쇼핑 경험에 대해서 편견 없이 탐색하고, 인상적인 경험의 내용을 구체적인 수준으로 범주화하려는 노력이 필요하다.

\section{Utilitarian vs. hedonic shopping values}

쇼핑 경험은 실용적 쇼핑 가치와 쾌락적 쇼핑 가치 의 두 가지 차원으로도 나뉠 수 있다(Babin, Darden \& Griffin, 1994). 이 때, 가치란 단순히 제품의 획득 으로부터 나오는 것이 아니라, 전반적인 쇼핑 경험 에서 얻을 수 있는 것으로, 소비자가 제품이나 서 비스와 상호작용하는 과정 중 상대적으로 선호되 는 경험을 뜻한다. Babin et al.(1994)에 의하면, 실 용적 쇼핑 가치는 특정한 소비자 욕구가 쇼핑을 통 해서 만족되었는지 여부에 초점을 맞추기 때문에, 소비자들은 쇼핑을 하나의 과업으로 여기고, 합리
적인 구매 의사 결정을 내리려는 경향이 있다. 반 면, 쾌락적 쇼핑 가치는 실용적 가치에 비해 주관 적이고 사적인 경험으로 쇼핑이 주는 즐거움이나 감정적인 가치에 초점을 맞춘다.

블랙 프라이데이의 쇼핑 경험 역시 경험의 어느 측면이 선호되느냐에 따라 실용적 쇼핑 가치와 쾌 락적 쇼핑 가치로 분류될 수 있을 것이다. 블랙 프 라이데이의 쇼핑 경험은 크게 가족의 긴밀한 유대, 전략적인 쇼핑 계획, 엄청난 경쟁, 임무 완료의 네 가지 양상으로 나눌 수 있는데(Jane Boyd \& Peters, 2011), 이 때 전략적인 쇼핑 계획이나 임무 완료와 같은 측면은 쇼핑을 하나의 과업으로 여기는 실용 적 쇼핑 가치에 해당한다. 반면, 블랙 프라이데이 쇼핑 중 지인에게 줄 선물을 고르면서 느끼는 즐거 움(Swilley \& Goldsmith, 2013)은 쇼핑이 주는 감정 적 중요성을 인정하는 쾌락적 쇼핑 가치로 볼 수 있다. 또한, 블랙 프라이데이에 관찰된 소비자 행동 에는 분노, 걱정, 지루함, 흥분, 행복, 긴장, 피곤함 등 다양한 감정이 나타났으며(Simpson et al., 2011), 이렇게 다양한 감정은 소비자가 블랙 프라이데이 쇼핑 중 느끼는 쾌락적 가치를 반영한다. 블랙 프 라이데이의 쇼핑 경험에 실용적 측면과 쾌락적 측 면이 있을 거라는 점은 선행연구의 결과로 미루어 추측할 수 있지만, 이를 뒷받침할 만한 경험적 근 거는 아직 불충분하다. 따라서 소비자의 블랙 프라 이데이 쇼핑 경험을 수집하여, 이를 실용적 가치 및 쾌락적 가치로 구분하여, 쇼핑 가치별 분류에 영향을 미칠 수 있는 요인으로는 어떤 것들이 있는 지 탐색해 볼 필요가 있다.

\section{Methods}

\section{Research questions}

블랙 프라이데이 쇼핑에 대한 소비자의 반응, 추 구 가치, 영향을 미치는 요인에 대해 탐색하기 위 해, 본 연구에서 설정한 연구문제는 다음과 같다.

연구문제 1. 소비자는 블랙 프라이데이 쇼핑에 대해 어떠한 반응을 보일까?

연구문제 2. 소비자의 블랙 프라이데이 쇼핑 경 험에서 나타나는 쇼핑 가치는 무엇인가? 
연구문제 3. 소비자의 블랙 프라이데이 쇼핑 경 험에 영향을 미치는 요인은 무엇인가?

\section{Critical incident technique}

본 연구에서는 결정적 사건기법(critical incident technique, CIT)을 활용하여 자료를 수집, 분석하였 다. 결정적 사건기법은 응답자의 언어를 통해, 그들 이 기억하고 있는 인상적인 경험의 속성을 분석하 기 위해 사용되는 기법이다(Choi \& Rha, 2011). 결 정적 사건기법은 소비자 경험을 보다 풍부하고 정확하게 측정한다는 점에서 양적 방법론을 보완 하며, 소비자 경험의 대표성 및 일반성에 초점을 맞춘다는 점에서 질적 방법론을 보완한다(Gremler, 2004). 즉, 응답자의 언어로 기술되기 때문에 설문 지를 활용한 양적 방법론에 비해 소비자 경험이 보 다 생생하고 구체적인 형태로 수집될 수 있다. 또 한 수집된 실제 사례들의 내용 분석을 통해 소비자 경험에 영향을 미칠 수 있는 요소들을 실증적으로 탐색할 수 있다. 특정 사례에 집중하기보다 다양한 사례가 공통적으로 보여주는 현상 그 자체를 분석 하기 때문에, 소비자 경험의 특수성에 치우칠 염려 가 적다. 아울러, 다양한 사례를 범주화하여 각 범주 의 빈도를 수치적으로 분석할 수 있기 때문에, 기존 질적 방법론보다 객관적인 결과를 제시할 수 있다.

Flanagan(1954)에 의하면, 결정적 사건기법은 응 답을 어떤 주어진 틀 안에 끼워 맞추는 게 아니라, 응답자의 관점을 있는 그대로 수용하여 자료를 수 집한다는 점에서 현상의 본질을 파악하기 용이하 다. 또한, 다수의 주요 사건에 초점을 맞추느라 간 과할 수 있는 소수의 특정 사건들까지 놓치지 않고 분석할 수 있다는 점에서, 결정적 사건기법은 다른 연구방법에 비해 차별적 우위점을 갖는다. 그러나 응답자의 기억에 의존하여 자료를 수집한다는 점 에서, 결정적 사건이 정확하게 묘사되지 않거나, 최 근에 일어난 사건 위주로 보고된다는 단점이 존재 한다. 블랙 프라이데이에 대한 기존 연구의 관점이 대체로 블랙 프라이데이의 경제적 순기능에 초점 을 맞추어 왔다는 점을 고려할 때, 본 연구에서는 블랙 프라이데이에 경험할 수 있는 소수의 특정 사 건까지 연구의 대상으로 포함한다는 점에서 결정 적 사건기법이 적합한 연구방법으로 사료된다. 아
울러, 블랙 프라이데이의 쇼핑 경험이 소비자의 언 어로 표현된다는 점에서 연구에 생동감을 줄 수 있 다. 또한, 블랙 프라이데이의 쇼핑 경험은 연속되는 사건이 아니라, 특정 시간 동안 한정되어 발생하는 사건이기 때문에, 최근에 일어난 사건 위주로 보고 된다는 결정적 사건기법의 편파성이 덜 영향을 미 칠 수 있다. 따라서 소비자의 블랙 프라이데이 쇼 핑 경험을 있는 그대로 수집하여 블랙 프라이데이 쇼핑에 대한 소비자의 반응, 추구 가치, 영향을 미 칠 수 있는 일반적인 요인을 도출하는 본 연구에서 는 결정적 사건기법이 적합한 연구방법이라고 판 단된다.

본 연구에서의 결정적 사건이란, 응답자들이 블 랙 프라이데이에 할인 행사를 진행 중인 상점을 방 문하여 쇼핑한 것으로 정의한다. 이 때 쇼핑은 상 품의 구매뿐 아니라, 구매와 상관없이 자기 만족이 나 기분 전환 등의 동기에 의해 정보 탐색을 하는 경우까지 포함한다(Shim, Jang \& Lee, 2008). 즉, 사 전에 특별한 구매 계획이 없고 실제로 상품을 구매 하지 않았어도 블랙 프라이데이에 할인 행사를 진 행한 상점을 방문했다면, 그 쇼핑 경험은 본 연구 의 결정적 사건에 해당한다.

\section{1) Sample}

본 연구의 모집단은 블랙 프라이데이에 할인 행 사를 진행하는 상점에 방문할 수 있는 소비자로 규 정되며, 편의표본추출법으로 자료를 수집하였다. 자 료 해석 이전에 고려해야 할 표본의 특성은 〈Table $1>$ 에 정리되어 있다. 표본은 미국 동남부 지역의 4 년제 대학에 재학 중인 생활과학대학 학부생 165 명 으로 구성되었으며, 이들의 평균 나이는 20.71세로 18 세부터 24 세까지 분포하였다. 블랙 프라이데이 가 특히 18 세부터 34 세 정도의 젊은 소비자들이 쇼 핑하도록 유인한다는 점을 미루어 볼 때(NRF, 2013), 표본의 연령 분포는 블랙 프라이데이 소비자 집단 보다 다소 어린 것으로 보인다. 표본의 성별 분포 는 남자 6 명, 여자 159 명으로 여성의 비율이 매우 높게 나타났다. 학부생 3학년(30.9\%)과 2학년(27.9\%) 의 참여가 과반수를 넘었고, 이어 1학년(23.6\%), 4 학년 $(17.6 \%)$ 순으로 설문에 참여하였다. 비라틴계 백인(89.1\%)이 표본의 대다수를 차지했으며, 전년 
$\langle$ Table 1〉 Demographic characteristics of the sample

$(n=165)$

\begin{tabular}{|c|c|c|c|}
\hline Variable & Category & $F$ & $\%$ \\
\hline \multirow{4}{*}{$\begin{array}{l}\text { Current } \\
\text { class in } \\
\text { school }\end{array}$} & Freshman & 39 & 23.6 \\
\hline & Sophomore & 46 & 27.9 \\
\hline & Junior & 51 & 30.9 \\
\hline & Senior & 29 & 17.6 \\
\hline \multirow{6}{*}{ Ethnicity } & Non-hispanic white & 147 & 89.1 \\
\hline & Non-hispanic black & 15 & 9.1 \\
\hline & Hispanic & 3 & 1.8 \\
\hline & Asian/pacific islander & 0 & 0.0 \\
\hline & American Indian/Alaskan native & 0 & 0.0 \\
\hline & Other & 0 & 0.0 \\
\hline \multirow{18}{*}{$\begin{array}{l}\text { Household } \\
\text { income } \\
\text { (Last year) }\end{array}$} & Under $\$ 5,000$ & 17 & 10.3 \\
\hline & $\$ 5,000$ to $\$ 9,999$ & 5 & 3.0 \\
\hline & $\$ 10,000$ to $\$ 14,999$ & 6 & 3.6 \\
\hline & $\$ 15,000$ to $\$ 19,999$ & 6 & 3.6 \\
\hline & $\$ 20,000$ to $\$ 24,999$ & 6 & 3.6 \\
\hline & $\$ 25,000$ to $\$ 29,999$ & 7 & 4.2 \\
\hline & $\$ 30,000$ to $\$ 39,999$ & 7 & 4.2 \\
\hline & $\$ 40,000$ to $\$ 49,999$ & 10 & 6.1 \\
\hline & $\$ 50,000$ to $\$ 59,999$ & 13 & 7.9 \\
\hline & $\$ 60,000$ to $\$ 69,999$ & 11 & 6.7 \\
\hline & $\$ 70,000$ to $\$ 79,999$ & 16 & 9.7 \\
\hline & $\$ 80,000$ to $\$ 89,999$ & 9 & 5.5 \\
\hline & $\$ 90,000$ to $\$ 99,999$ & 10 & 6.1 \\
\hline & $\$ 100,000$ to $\$ 124,999$ & 13 & 7.9 \\
\hline & $\$ 125,000$ to $\$ 149,999$ & 9 & 5.5 \\
\hline & $\$ 150,000$ to $\$ 199,999$ & 7 & 4.2 \\
\hline & $\$ 200,000$ to $\$ 249,999$ & 4 & 2.4 \\
\hline & $\$ 250,000$ or over & 9 & 5.5 \\
\hline
\end{tabular}

도 가계소득에서는 비교적 고른 분포를 보였다. 학 년 비중과 전년도 가계소득을 제외한 나머지 인구 통계학적 특성에서 다소 편향된 양상을 보이기 때 문에, 자료를 해석할 때 이러한 표본의 특성을 함 께 고려해야 할 것이다.

\section{2) Data collection}

자료의 수집은 온라인 설문 조사 형태로 진행되
었다. 설문지에는 응답자가 직접 쇼핑 수기를 작성 하도록 요청하는 서술형 문항이 사용되었다: “귀하 께서 블랙 프라이데이에 할인 행사를 진행 중인 상 점에서 쇼핑했던 경험 중, 가장 인상 깊었던 기억 을 떠올려 주십시오. 지금 귀하께서 떠올린 인상적 인 경험을 자유롭게 묘사해 주십시오." 결정적 사 건을 묻는 서술형 문항에 더불어, 결정적 사건의 선행사건 및 결과와 관련된 내용 역시 설문에 포함 되었다: “무엇을 구입했습니까? 쇼핑 전에 계획된 구매였습니까? 정가에 비해 얼마를 지불할 거라고 예상했습니까? 구매에 만족했습니까? 그 이유는 무 엇입니까?” 이런 추가적인 문항들은 응답자의 쇼핑 경험 회상을 도와, 보다 풍부한 진술을 이끌어내고 보다 정확한 자료를 수집하는 데 도움을 준다(Choi \& Rha, 2011). 결정적 사건에 대한 문항 이외에, 나 이, 성별, 학년, 전공, 인종, 전년도 가계수입과 같 은 인구통계학적 특성을 묻는 질문도 추가되었다. 설문은 미국 동남부 지역의 4년제 대학에 개설 된 강의의 수강생 약 300 명에게 참여를 독려하여 이루어졌다. 해당 강의의 강사들에게 허락을 구한 후, 교내 메일 시스템을 활용하여 수강생들에게 단 체 전자메일을 발송하였다. 전자메일의 내용은 본 연구에 대한 소개와 온라인 설문 조사에 참여할 수 있는 URL로 구성되었다. 회수된 설문 응답은 총 257부였으며, 이 설문 응답들은 앞서 본 연구에서 정의한 결정적 사건의 조건을 충족하는지 검토되 었다. 기준 조건은 다음과 같다.

- 결정적 사건은 블랙 프라이데이에 일어나야 한다.

- 결정적 사건은 블랙 프라이데이를 위한 할인 행사를 진행 중인 상점에서 일어나야 한다.

- 결정적 사건은 상품의 구매뿐 아니라, 구매와 상관없이 자기 만족이나 기분 전환 등의 동기 에 의해 정보 탐색을 하는 경우까지 포함한다.

결정적 사건의 정의에 부합하지 않는 58 부의 응 답이 제외되었다. 이 중 55부는 블랙 프라이데이에 쇼핑하지 않는다고 답했으며, 3 부는 응답이 불성실 했다. 이어서, 응답자의 전공이 분석 결과에 미칠 수 있는 예기치 않은 효과를 통제하기 위하여 응답 의 대다수를 차지하는 생활과학대학 학생 173 명의 
응답만을 분석 대상으로 삼았다. 이 중, 대학원생 8 명의 응답 역시 교육수준의 차이에서 오는 예기치 못한 영향을 통제하기 위하여 분석에서 제외되었 다. 따라서 총 165 부의 응답이 분석에 사용되었다.

\section{3) Data analysis}

Flanagan(1954)와 Gremler(2004)이 제안한 결정 적 사건 분석 절차에 따라, 165 부의 응답은 일차적 으로 긍정적 경험과 부정적 경험으로 분류되었다. 이 때, 하나의 응답 안에 긍정적 경험과 부정적 경 험이 혼재하면, 이를 분절하여 두 개의 결정적 사 건으로 코딩하였다. 따라서 분석에 사용된 총 결정 적 사건의 수는 198 개였다. 결정적 사건의 코딩은 두 명의 코더(coder)가 독립적으로 진행하였고, 코 더 간 신뢰도(inter-coder reliability)는 .70보다 높은 .95로 나타나, 코딩 결과의 내적 일관성을 확보하였 다 (Miles \& Huberman, 1994). 코더 간 분류가 불일 치한 결과에 대해서는 두 코더가 대면하여 논의를 거쳐 의견을 수렴하였다. 긍정적 혹은 부정적 경험 으로 분류 후, 결정적 사건은 다시 Babin et al.(1994) 이 제안한 쇼핑 가치의 두 차원을 기준으로 유사한 내용끼리 묶여 실용적 혹은 쾌락적 쇼핑 경험의 공 통 주제(common themes)로 분류되었다. 이 때, 코 더 간 신뢰도는 .91으로 내적 일관성을 확보하였으 며, 불일치한 결과는 코더 간 논의를 통해 의견을 수렴하였다. 이어서, 쇼핑 경험에 대한 긍정적/부정 적 반응과 실용적/쾌락적 쇼핑 가치에 의해 분류된 4개 집단을 다시 범주(categories)로 분류하기 위해 각 집단의 결정적 사건을 신중하고 반복적으로 검 토하였다. 두 명의 코더가 독립적으로 결정적 사건 을 유사한 내용끼리 묶어 그 결과를 비교하였으며, 이 때 코더 간 신뢰도는 .88 로 내적 일관성을 확보 하였다. 일치하지 않은 결과에 대해서는 논의를 거 쳐 의견을 수렴하였고, 그 결과 4개 집단을 통틀어 12 개의 범주를 최종적으로 도출하였다.

\section{Results and Discussion}

1. Positive versus negative, utilitarian versus hedonic shopping experiences

총 198 개의 결정적 사건 중, 긍정적 쇼핑 경험은
123 개(62.2\%), 부정적 쇼핑 경험은 75 개( $37.8 \%)$ 로 나타났으며, 각 반응에서 도출된 공통 주제로 실용 적 쇼핑 경험과 쾌락적 쇼핑 경험이 나타났다(Fig. 1). 긍정적 쇼핑 경험 중 실용적 경험은 65 개 $(52.8 \%)$, 쾌락적 경험은 58 개(47.2\%)였고, 부정적 쇼핑 경험 중 실용적 경험은 33 개(44.0\%), 쾌락적 경험은 42 개 $(56.0 \%)$ 로 나타났다. 쇼핑 경험에 대한 반응(긍정/ 부정)과 쇼핑 가치(실용적/쾌락적)가 독립적인지 검 증하기 위해 카이제곱 검정을 실시한 결과, 두 변 수는 독립적인 것으로 나타났다 $\left(\chi^{2}=1.458, d f=1, p=\right.$ .227). 즉, 쇼핑 경험에 대해 긍정적 혹은 부정적 반 응을 보이는 것과 실용적 혹은 쾌락적 쇼핑 가치를 느끼는 것 사이에는 유의한 상관관계가 발견되지 않아, 서로 영향을 주는 관계가 아닌 독립적인 관 계라고 볼 수 있다.

\section{Description of categories}

위 네 가지 분류는 다시 12 개의 범주로 나뉘어 졌다. 먼저, 긍정적 쇼핑 경험 중 실용적 쇼핑 가치 와 관련이 있는 결정적 사건은 주로 저렴한 가격 $(F=$ $58,89.2 \%)$ 에 대한 내용이었고, 고가 제품에 대한 구매 $(F=7,10.8 \%)$ 에 대한 언급도 나타났다. 이와 더 불어, 긍정적 쇼핑 경험 중 쾌락적 쇼핑 가치로 분 류된 결정적 사건은 충동 구매( $F=32,55.2 \%)$, 휴일 분위기 $(F=16,27.6 \%)$, 최신 혹은 고급 브랜드 제품 에 대한 구매 $(F=10,17.2 \%)$ 의 범주로 나타났다. 반 면, 부정적 쇼핑 경험 중 실용적 쇼핑 가치와 관련 된 결정적 사건은 미미한 할인폭 $(F=9,27.3 \%)$, 품절 $(F=9,27.3 \%)$, 줄서기 위한 시간 투자 $(F=8,24.2 \%)$, 휴일 쇼핑으로 인한 피로 $(F=7,21.2 \%)$ 와 관련된 비 교적 다양한 범주가 도출되었다. 마지막으로, 부정 적 쇼핑 경험 중 쾌락적 쇼핑 가치로 분류된 결정 적 사건은 북적거리는 환경 $(F=32,76.2 \%)$, 강박 구 매 $(F=6,14.3 \%)$, 관리가 허술한 매장 $(F=4,9.5 \%)$ 에 대한 범주가 나타났다. 각 범주에 대한 자세한 설 명은 다음과 같다.

\section{1) $1 \mathrm{~A}$. Off-price shopping}

저렴한 가격 범주는 긍정적이면서 실용적 가치 를 인정하는 블랙 프라이데이 쇼핑 경험 중 압도적 으로 많이 언급되었다. 블랙 프라이데이에 제공되 


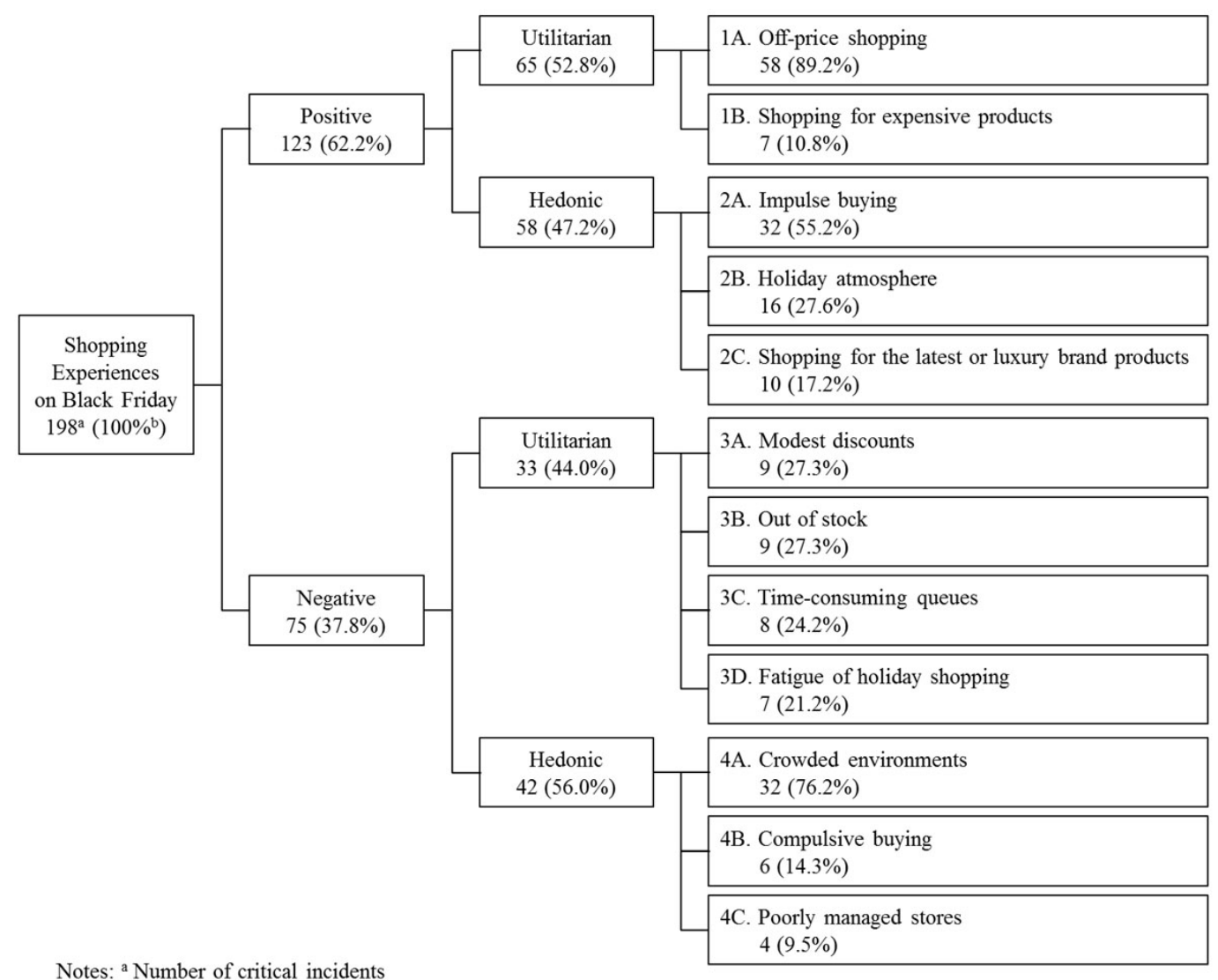

${ }^{b}$ Percentage of critical incidents (relative to category/subcategory total)

〈Fig. 1〉 Critical incidents of shopping experience on Black Friday

는 저렴한 가격 덕에 소비자들이 전반적인 쇼핑에 만족하는 결정적 사건이 빈번하게 발견되었다. 저 렴한 가격 범주에 포함되는 결정적 사건은 정가와 비교해서 얼마나 할인을 받았는지, 그리고 소비자 가 원래 예상했던 지출 수준에 비해 얼마나 예산을 아낄 수 있었는지에 초점이 맞추어져 있었다. 또한 쇼핑 경험의 다른 측면이 다소 불만족스럽다고 할 지라도 저렴한 가격이 주는 이득이 이런 부정적인 측면을 상쇄시키는 측면도 발견되었다. 이러한 결 과를 고려하면, 패션 유통업체에서 의도적으로 기 획하는 블랙 프라이데이 상품 및 할인 전략은 실용 적 쇼핑을 선호하는 소비자들에게 주효할 것으로 보인다. 저렴한 가격 범주에 포함된 결정적 사건의 인용 예시는 다음과 같다.
- $\$ 100$ 는 지출할 거라 예상했는데, 사실상 $\$ 60$ 만 지출했어요. $\$ 40$ 나 절약했다는 사실에 만 족했던 기억이 나요.

- 블랙 프라이데이에 버밍햄에 있는 Galleria 에 갔었어요. 저보다는 엄마가 구매를 많이 했죠. 대부분 가족들 줄 크리스마스 선물이었는데, 할인을 엄청 많이 받아서 엄마가 굉장히 좋아 했어요.

- 최소한 정가보다 $30 \%$ 싸게 살 수 있을 거라고 예상했는데, 실제로도 딱 그 정도 할인 받았어 요. 우리가 사고 싶어했던 제품을 구매할 수 있어서 굉장히 만족했죠. 기다리는 거야 어렵 지 않으니까요. 인내심과 계획성 덕분에, 우리 가 원하던 $T V$ 를 저렴한 가격에 구매할 수 있 
었어요. 이 정도 거래는 할 만한 것 같아요.

\section{2) 1B. Shopping for expensive products}

긍정적이면서 실용적 가치를 인정하는 블랙 프 라이데이 쇼핑 경험으로, 고가 제품에 대한 구매를 나타낸 결정적 사건도 있었다. 이 범주에서는 소비 자들이 블랙 프라이데이 쇼핑을 위한 사전 계획을 세울 때 가능한 많은 돈을 아끼기 위하여 정가 자 체가 높게 책정된 고가 제품을 구매하려고 하는 모 습이 나타난다. 유통업자마다 $50 \%$ 나 $70 \%$ 같은 일 정한 할인율을 제공하기 때문에, 정가 자체가 높으 면 할인 받을 수 있는 금액도 많아지기 때문이다. 특히, TV나 GPS 네비게이션 시스템 같은 전자기기 에 대한 쇼핑이 이 범주에 주로 포함되었다. 이에 따라, 실용적 쇼핑 가치 성향의 소비자들에게 긍정 적인 블랙 프라이데이 쇼핑 경험을 제공하기 위해 서는 고가 제품에 대한 할인 기획에 주력하는 것이 도움이 될 것으로 보인다. 고가 제품에 대한 구매 범주와 관련된 인용 예시는 다음과 같다.

- 저의 아버지는 항상 이른 아침에 일어나서 Best $B u y$ 를 가죠. 할인된 가격에 가전제품을 사려 고요 전자액자도 사고, 차량에 장착할 GPS 네 비게이션 시스템도 두 개나 사 왔어요 얼마나 할인된 가격으로 산 건지 말씀은 안 하시지만, 그 구매에 정말 만족하시더라고요.

- 한 번은 우리 가족이 블랙 프라이데이 시즌에 유명 전자제품 상점에서 $T V$ 를 사려고 계획했 던 적이 있어요 우리는 사려는 제품을 찍어놓 고, 그 제품이 할인할 때까지 기다렸죠.

-Wal-Mart에 가서 네비게이션 시스템을 하나 샀던 기억이 있어요. 엄마랑 전 그 제품을 광 고에서 본 적이 있었고, Wal-Mart에 가기 전 에 이미 그 제품을 사야겠다고 계획하고 있 었죠.

\section{3) 2A. Impulse buying}

충동 구매 범주는 긍정적이면서 쾌락적 가치를 인정하는 블랙 프라이데이 쇼핑 경험 중 가장 많이 언급되었다. 소비자들은 딱히 구매 계획이 있지는 않았지만, 쇼핑 과정 중 충동적으로 구매를 하게
되었으며, 구매 결과에 대해 만족하였다. 충동 구매 를 하게 된 원인으로는 큰 할인폭에 대한 놀라움, 흥분, 성급함 등의 감정적 동인이 발견되었다. 그러 나 일반적으로, 할인된 가격 외에도 소비자 개인적 신념(Verhagen \& van Dolen, 2011)이나 미적 환경 (Wang, Minor \& Wei, 2011) 등 다양한 요인이 소비 자의 감정을 자극하여 충동 구매를 이끌 수 있다는 선행연구의 결과를 고려해 보면, 본 연구의 결과는 소비자들이 블랙 프라이데이에 쇼핑을 할 때 가격 할인 자체에 굉장히 몰입해 있다는 것을 보여준다. 충동 구매 범주에 포함된 결정적 사건의 인용 예시 는 다음과 같다.

·J. Crew 에서 스웨터를 $40 \%$ 할인된 가격으로 샀어요. 딱히 사야겠다고 계획한 거 없이 매장 에 방문했는데, 마음에 드는 디자인이 그 가격 인 거에요. 보물 찾은 거 같았죠. 바로 즉석으 로 사기로 마음먹었어요.

- 하나에 $\$ 5$ 씩 영화 DVD 2 편을 샀어요. 쇼핑 가 기 전까지는 딱히 살 계획이 없었는데, 보통은 하나당 $\$ 20$ 는 줘야 하잖아요. $\$ 5$ 만 지불하면 된다는 점에서 광장히 만족했어요.

$\cdot 50 \%$ 할인 받았어요. 휠씬 더 비쌀 줄 알았고, 사실 상점으로 들어가기 전까진 사려는 계획 이 없었어요. 어쨌든 결과는 만족스러워요.

- 정가가 대충 $\$ 250$ 정도였는데, $\$ 130$ 에 샀어요. 세상에! 누가 사가기 전에 일단 집어야겠다는 생각이 들었어요. 매우 만족스러운 구매였죠. 이래서 전 블랙 프라이데이가 너무 좋아요 원 래는 1 개나 2개를 사려고 했었는데, 결과적으 로 4 개나 사 버렸어요.

\section{4) 2B. Holiday atmosphere}

휴일 분위기 범주는 긍정적이면서 쾌락적 가치 를 인정하는 블랙 프라이데이 쇼핑 경험에 속하며, 블랙 프라이데이에 쇼핑 센터 전반적으로 흐르는 활기차고 들뜬 명절의 분위기가 결정적 사건으로 묘사되었다. 가족이나 친구들끼리 무리지어 휴일을 즐기는 모습이나 만족스런 쇼핑에 즐거워하는 모 습, 축제와 같은 분위기가 언급되었으며, 인용 예시 는 다음과 같다. 
- 전 블랙 프라이데이가 좋아요. 소매점에서 일 용직으로 몇 번 일해 봤는데, 하루 종일 바브 게 움직일 수 있고, 사람들이 그 세일을 너무 좋아한다는 걸 아니까요.

- 친구랑 쇼핑을 가죠. 군이 뮐 사지 않더라도, 그 가격에 아무것도 안 사긴 힘들지만, 그 에 너지 넘치는 분위기가 좋아요. 그냥 재밌어요.

\section{5) 2C. Shopping for the latest or luxury brand} products

긍정적이면서 쾌락적 가치를 인정하는 블랙 프 라이데이 쇼핑 경험으로, 최신 혹은 고급 브랜드 제품에 대한 구매 범주도 나타났다. 이 범주에서는 소비자들이 블랙 프라이데이 쇼핑을 하면서 최신 제품이나 고급 유명 브랜드 제품을 저렴한 가격으 로 구매했을 때 즐거워하거나 흥분하는 모습이 나 타났다. 특히, 의류나 액세서리 등 패션 제품에 대 한 쇼핑 경험이 이 범주에 주로 포함된다는 점을 미루어 볼 때, 패션 신제품이나 유명 브랜드의 패 션 제품에 대해 블랙 프라이데이 기획 물량을 확대 한다면 패션 유통업체가 소비자에게 긍정적인 쇼 핑 경험을 제공할 수 있을 것이다. 최신 혹은 고급 브랜드 제품에 대한 구매에 해당하는 인용 예시는 다음과 같다.

-Ray-Bans 선글라스를 샀고... 잘 알려진 브랜 드니까요. 정가로 사려면 돈을 더 많이 내야 하는데, 저렴한 가격에 유명 브랜드 제품을 살 수 있어서 좋았죠.

- 신상품이 이렇게 많이 할인되는 경우는 흔치 않아요. 흥분해서 Coach 가방을 여러 개 샀어 요. 엄마랑 언니랑 나눠주려고요.

- 영화 $D V D \cdots$ 개봉한지 얼마 안 된 최신 영화 라서 바로 구매해야겠다고 생각했어요.

\section{6) 3A. Modest discounts}

미미한 할인폭 범주는 부정적이면서 실용적 가 치와 연관 있는 블랙 프라이데이 쇼핑 경험에 속한 다. 이 범주에서는 소비자가 블랙 프라이데이 쇼핑 은 다른 날 쇼핑하는 것보다 난이도가 높은 과업으 로 여기며, 쇼핑 결과에 만족하기 위해서는 도전적
인 과업에 따른 보상으로 할인폭이 굉장히 커야 한 다는 것을 강조한다. 즉, 실제로 가격 할인 정도가 낮다는 절대적인 인식이 아니라, 들어가는 노력에 비해서 보상이 약하다는 상대적인 인식이 작용하 는 것이다. 따라서 이러한 부정적 쇼핑 경험을 긍 정적 쇼핑 경험으로 전환하기 위해서는, 더 파격적 인 가격할인을 단행하는 것보다 소비자가 들여야 하는 노력을 줄이는 게 주효할 것으로 보인다. 미 미한 할인폭 범주에 포함된 결정적 사건의 인용 예 시는 다음과 같다.

" “할인된 가격” 이라는 것도 그 요란 떠는 거에 비하면 별 가치 없다고 생각해요.

- 제 경험상, 저는 $\$ 100$ 이상 할인 받을 수 있는 경우에만 블랙 프라이데이에 쇼핑하러 가요. 사람이 너무 많으면 할인 받는 게 가치가 없 죠. 할인된 가격은 정말 많은 사람을 불러 모 으기 때문에, 할인폭이 클 때만 그 할인이 의 미가 있는 것 같아요.

\section{7) 3B. Out of stock}

부정적이면서 실용적 가치와 연관 있는 블랙 프 라이데이 쇼핑 경험으로 품절 범주도 나타났다. 이 범주에서는 소비자들이 저렴한 가격에 제품을 구 매하고 싶었으나, 부족한 제품 수량 때문에 구매에 실패한 결정적 사건이 포함된다. 유통업자들은 많 은 잠재 고객을 유인하면서 동시에 높은 수익을 얻 기 위해, 몇몇 한정된 수량의 제품만 파격적인 가 격을 제시한다. 따라서 이러한 제품을 구매하기 위 해 소비자들간 경쟁이 매우 치열해지며, 그 과정에 서 소비자들은 품절과 구매 실패라는 부정적인 경 험을 갖게 된다. 이러한 부정적 경험의 개선을 위 해서는 재고 회전율을 높이거나, 품절된 상품을 다 른 상품을 대체하여 소비자가 구매 기회를 상실하 지 않도록 하는 유통업체의 노력이 필요하다. 이 범주에 대한 인용 예시는 다음과 같다.

- 제가 매장에 갔을 때는 이미 대부분 쓸 만한 물건들은 다 동이 났어요. 살 게 없더라고요. 사려고 계획했던 건 여러 개였는데, 그 중에 하나밖에 못 샀어요. 이럴 거면 그냥 집에서 
있을 걸 $\cdots$ 이런 생각도 들고.

\section{8) 3C. Time-consuming queues}

줄서기 위한 시간 투자 범주는 부정적이면서 실 용적 가치와 연관 있는 블랙 프라이데이 쇼핑 경험 으로 분류된다. 근래 유통업자들이 블랙 프라이데 이 영업시간을 자정부터 혹은 새벽부터 시작하는 것으로 앞당기고, 이러한 새벽 시간대에 한시적으 로 파격적인 할인률을 적용하자, 소비자들이 이에 맞추어 매장 앞에 줄을 서고 문을 열기를 기다리는 등 블랙 프라이데이 쇼핑을 계획대로 성공적으로 완수하기 위해 오랜 시간을 투자하는 모습이 나타 난다. 이러한 시간 투자는 앞서 제시한 미미한 할 인폭 범주와 연관될 수 있다. 즉, 소비자가 많은 시 간을 투자하는 만큼 그 노력에 보상받기 위해서 매 우 큰 가격 할인을 기대할 수 있고, 실제 할인폭에 대해서 미미하다고 인지하며 실망할 수 있다. 따라 서 유통업체들은 이렇게 소비자를 줄 세우고 구매 경쟁을 유도하는 것이 과연 효과적인 전략인지 점 검해 볼 필요가 있다. 줄서기 위한 시간 투자 범주 와 관련된 인용 예시는 다음과 같다.

- 우리 가족은 항상 블랙 프라이데이에 쇼핑을 가요. 새벽 4시에 일어나서 새벽 5 시까지 상점 에 도착해서 줄을 서죠. 그렇게 일찍 움직여야 우리가 가기 전에 미리 봐놨던 물건들은 계획 대로 살 수 있어요. 줄 서는 거 자체는 괴롭지 만 경쟁이 치열해서 어쩔 수 없죠.

- 사람도 많고 아침 일찍부터 줄을 서야 되기 때 문에, 저는 블랙 프라이데이 쇼핑에 전혀 관심 없어요.

- 여동생과 함께 새벽 3 시부터 상점에 갔어요. 이미 미칠 듯이 붐벼서 매우 짜증났죠 사람이 많으면 아무래도 사려고 했던 물건이 일찍 동 날 수 있으니까요.

\section{9) 3D. Fatigue of holiday shopping}

부정적이면서 실용적 가치와 연관 있는 블랙 프 라이데이 쇼핑 경험으로 휴일 쇼핑으로 인한 피로 범주도 나타났다. 이 범주에서는 열악한 쇼핑 환경 에서 오는 소비자의 정신적 스트레스가 결정적 사
건으로 묘사되며, 소비자의 계획 구매에 대한 저해 요인으로 작용한다. 이 범주 역시 소비자가 블랙 프라이데이 쇼핑을 위해 들이는 노력과 관련이 있 기 때문에, 유통업체들은 휴일 쇼핑으로 인한 피로 를 어떻게 감소시킬지에 더 관심을 기울여야 한다. 이 범주의 인용 예시는 다음과 같다.

· 청바지를 사려고 했었는데, 당일 늦잠을 자버 려서 제 시간에 도착하지 못했어요. 너무 경쟁 이 치열하기도 했고, 제가 그런 걸 즐기는 성 격의 사람도 아니고.

· 블랙 프라이데이 세일 때 크리스마스 선물을 몇 개 샀어요 원래 더 많이 사려고 했었는데, 그 쇼핑 경험을 즐기기엔 너무 사람이 많았죠 금 방 지쳐서 쇼핑을 계속 할 의욕을 상실했어요

- 블랙 프라이데이는 쇼핑하기에 1년 중 가장 북적거리는 날이에요. 광장히 많은 소비자들 이 할인된 가격에 물건을 사려고 모인다는 것 을 쉽게 예상할 수 있죠.

\section{0) 4A. Crowded environments}

북적거리는 환경 범주는 부정적이면서 쾌락적 가치를 인정하는 블랙 프라이데이 쇼핑 경험 중 압 도적으로 많이 언급되었다. 블랙 프라이데이 쇼핑 을 위해 굉장히 많은 인파가 한꺼번에 몰리면서, 불쾌한 쇼핑 환경으로 인한 짜증과 스트레스에 대 한 결정적 사건이 주를 이루었다. 이에 따라, 북적 거리는 쇼핑 환경을 개선하려는 유통업체의 노력 이 시급한 것으로 보인다. 모든 할인을 특정 시간 부터 일괄적으로 적용하는 것보다 시간대를 분산 시켜서 적용하는 등 소비자의 흐름을 분산시키려 는 전략을 개발하는 것은 소비자의 불쾌감을 완화 시키는 데 도움을 줄 수 있다. 북적거리는 환경 범 주의 인용 예시는 다음과 같다.

- 정말 그 날은 장난 아니에요. 사람이 북적이는 거에 정말 스트레스를 많이 받기 때문에 상상 만 해도 싫어요. 교통도 막히고 북적북적한 사 람들을 피해 다니느라 나가 봐야 오히려 손해 에요.

- 뉴욕에 있는 FAO Schwarz 매장에 갔었던 기 
억이 있는데, 결국 아무것도 사지 않고 그냥 나왔죠. 말도 안 될 정도로 많은 사람들이 매 장을 가득 채우고 있었거든요.

\section{1) 4B. Compulsive buying}

강박 구매 범주는 부정적이면서 쾌락적 가치와 관련 있는 블랙 프라이데이 쇼핑 경험에 속한다. 구매 계획이 없었지만, 블랙 프라이데이 분위기 상 뭐라도 구매해야 할 것 같은 기분 때문에 구매했다 는 결정적 사건이 기술되었다. 대대적인 할인 때문 에 뭐라도 사지 않으면 손해 보는 것 같은 기분, 무 언가를 구매하려는 사람들로 북적거리는 매장, 소 비자 개인이 이미 쇼핑에 투자한 시간과 노력 등에 의해 강박 구매가 이루어지는 것으로 보인다. 이 범주에 대한 인용 예시는 다음과 같다.

- Express 에서 클러치 지갑 하나만 샀던 거 같아 요. 좋은 구매는 아니었던 거 같아요. 사고 싶 어서 산 것보다는 뮈라도 사야 될 것 같은 기 분이 들어서 산 것뿐이에요.

\section{2) 4C. Poorly managed stores}

관리가 허술한 매장 범주는 부정적이면서 쾌락 적 가치와 관계된 블랙 프라이데이 쇼핑 경험으로 분류된다. 이 범주에서는 소비자들이 쾌적하지 않 은 매장 환경이나 제대로 응대해 주지 않는 매장 점원에 대한 감정적 대응이 묘사된다. 이러한 결과 로 미루어 볼 때, 유통업체는 가격 할인에 의한 매 출 증대에만 초점을 맞추지 말고, 전반적인 소비자 경험을 고려한 쇼핑 환경 개선에도 관심을 기울여 야 하겠다. 관리가 허술한 매장과 관련된 인용 예 시는 다음과 같다.

- 옷들이 산처럼 수북하게 쌓여있었는데 뮌가 하자가 있는 상품들 같아 보였어요. 거기서 뮐 하나 건져보겠다고 옷들을 뒤질 기분은 아니 었어요.

- 일용직으로 고용된 점원들은 뮐 물어봐도 잘 모르고, 친절하지도 않고, 그렇다고 너저분해 진 매장을 깔끔하게 정리하는 것도 아니고... 바쁘게 뛰어다니기는 하는데 정작 제가 서비
스를 받는다는 느낌은 없어요.

\section{Conclusion}

본 연구는 블랙 프라이데이에 할인 행사를 진행 하는 상점에 방문할 수 있는 소비자를 대상으로 블 랙 프라이데이 쇼핑 경험을 수집하고, 이를 결정적 사건기법을 활용하여 분석함으로써 블랙 프라이데 이 쇼핑에 대한 소비자의 반응, 추구 가치, 영향을 미치는 요인에 대해 탐색하였다. 결정적 사건기법 을 통해 198 개의 블랙 프라이데이 쇼핑 경험을 분 석한 결과, 긍정적 쇼핑 경험뿐만 아니라, 부정적 쇼핑 경험도 상당한 비중으로 언급되었다는 점이 주목할 만하다. 각 반응에서 도출된 공통 주제로는 실용적 쇼핑 가치와 쾌락적 쇼핑 가치가 나타났으 며, 이와 더불어 소비자의 블랙 프라이데이 쇼핑 경험에 영향을 미칠 수 있는 12 개의 범주가 도출되 었다. 긍정적이고 실용적인 쇼핑 경험은 주로 저렴 한 가격에 기인하는 것으로 나타났으며, 고가 제품 구매와도 관련이 있었다. 긍정적이고 쾌락적인 쇼 핑 경험은 충동 구매, 활기찬 분위기, 최신 혹은 유 명 브랜드 제품에 대한 구매와 관련이 있는 것으로 나타났다. 반면, 부정적이고 실용적인 쇼핑 경험은 미미한 할인폭, 품절, 줄서기 위한 시간 투자, 휴일 쇼핑으로 인한 피로와 같이 다양한 범주에 의해 영 향을 받는 것으로 나타났다. 마지막으로, 부정적이 고 쾌락적인 쇼핑 경험은 북적거리는 환경, 강박 구매, 관리가 허술한 매장과 관련이 있는 것으로 나타났다.

본 연구의 결과는 블랙 프라이데이의 경제적 효 과에 비해 상대적으로 주목 받지 못했던 소비자의 쇼핑 경험을 분석한 결과로, 연휴 기간의 쇼핑에서 볼 수 있는 독특한 소비자 행동을 이해하는 데 실 증적 토대를 제공하였다는 점에서 학문적으로 의 의가 있다. 선행연구에 근거하여 블랙 프라이데이 의 쇼핑 경험이 긍정적 혹은 부정적, 또한 실용적 혹은 쾌락적 경험으로 나누어질 수 있다는 점을 밝 혔으며, 이러한 결과는 후속연구에서 이론적 틀로 사용됨으로써, 연휴 기간의 쇼핑에 나타나는 소비 자 행동 연구의 발전에 기여할 수 있다.

이와 더불어, 본 연구의 결과는 패션 유통업체들 
이 블랙 프라이데이의 단기적 매출 증진 효과에만 중점을 두지 않고, 소비자의 쇼핑 경험을 개선하여 고객과의 장기적 관계를 발전시켜야 하는 필요성 을 강조했다는 점에서 실용적 의의가 있다. 소비자 의 경험 측면에서 보면, 블랙 프라이데이 쇼핑에 대해 긍정적 반응뿐 아니라, 부정적 반응도 보여, 패션 유통업체의 블랙 프라이데이 쇼핑 기획 시 개 선의 여지가 있다는 점을 시사하였다. 특히 부정적 경험 중 쾌락적 가치의 범주 중 북적거리는 환경에 대한 불평이 두드러지게 나타났다. 이에 따라 소비 자의 부정적인 쇼핑 경험을 긍정적인 쇼핑 경험으 로 전환시키려는 노력이 필요하다. 예를 들면, 패션 유통업체가 시간대에 따라 다양한 할인 정책을 펼 쳐 매장을 방문한 소비자를 전략적으로 분산시킨 다면 블랙 프라이데이의 쇼핑 경험은 보다 긍정적 으로 평가될 수 있다.

본 연구의 한계점 및 후속연구를 위한 제안은 다 음과 같다. 첫째, 본 연구는 결정적 사건기법을 활 용한 질적 연구로 소비자의 인상적인 쇼핑 경험을 다각도로 탐색할 수 있다는 장점이 있으나, 쇼핑 경험에 영향을 미치는 요인 간 영향력의 크기라든 지, 요인 간 구조를 검증하기에는 한계가 있다. 따 라서 후속연구에서는 본 연구의 결과를 정량적으 로 검증할 수 있도록 블랙 프라이데이 쇼핑 행동에 대한 양적 연구가 필요할 것으로 사료된다. 둘째, 본 연구에서 사용된 표본은 성별 및 인종에서 각각 여성과 백인의 비중이 높게 나타나, 다소 편향되었 다. 이에 따라, 후속연구에서 보다 대표성 있는 표 본을 추출하여 본 연구의 결과를 재현하는 것도 의 미있는 작업이 될 것이다. 셋째, 본 연구에서는 블 랙 프라이데이에 소비자가 쇼핑하는 제품군을 특 별히 한정시키지 않고 광범위하게 탐색하였다. 패 션상품과 같이 특정 상품군에 대한 소비자의 블랙 프라이데이 쇼핑 경험은 후속연구를 통해 더 깊게 이해할 수 있을 것이다.

\section{References}

Ahn, M.(2014). [Retailing] 11st., 'Shocking Friday' promotional event launched. Hankook Ilbo. Retrieved April 22, 2014, from http://news.hankooki.com/ lpage/economy/201403/h2014032716254421580. $\mathrm{htm}$

Babin, B. J., Darden, W. R., \& Griffin, M.(1994). Work and/or fun: Measuring hedonic and utilitarian shopping value. Journal of Consumer Research, 20(4), 644-656.

Ballard, P.(2011). Customer experience is hot. New Media Age, 25.

Biedenbach, G., \& Marell, A.(2010). The impact of customer experience on brand equity in a business-to-business services setting. Journal of Brand Management, 17(6), 446-458.

Carr, D.(2008). Media and retailers both built Black Friday. New York Times. Retrieved April 22, 2014, from http://www.nytimes.com/2008/12/01/ business/media/01 carr.html?_r=1\&ref=media

Cho, K.(2014). [Three-year blueprint for innovations in ecomony] The Korea chamber of commerce $\&$ industry is considering introducing 'Korean version of Black Friday'. The Asia Economy Daily. Retrieved April 22, 2014, from http:// view.asiae.co.kr/news/view.htm?idxno=20140225 12294985095

Choi, A.-y., \& Rha, J.-Y.(2011). Understanding the consumer experience in retailing channel using critical incident technique. Korean Journal of Human Ecology, 20(6), 1185-1198.

Flanagan, J. C.(1954). The critical incident technique. Psychological Bulletin, 15(4), 327-358.

Gremler, D. D.(2004). The critical incident technique in service research. Journal of Service Research, 7(1), 65-89.

Grewal, D., Levy, M., \& Kumar, V.(2009). Customer experience management in retailing: An organizing framework. Journal of Retailing, 85(1), 1-14.

Grewal, D., Roggeveen, A. L., Compeau, L. D., \& Levy, M.(2012). Retail value-based pricing strategies: New times, new technologies, new consumers. Journal of Retailing, 88(1), 1-6.

Jane Boyd, T., \& Peters, C.(2011). An exploratory investigation of Black Friday consumption rituals. 
International Journal of Retail \& Distribution Management, 39(7), 522-537.

Lee, S.(2014). Rapidly increasing purchases through international online shopping websites $\cdots$ Now buy marriage stuff directly from overseas retailers! Media It. Retrieved April 22, 2014, from http:// www.it.co.kr/news/mediaitNewsView.php?nSeq= 2605154

Lennon, S. J., Johnson, K. K. P., \& Lee, J.(2011). A perfect storm for consumer misbehavior: shopping on Black Friday. Clothing and Textiles Research Journal, 29(2), 119-134.

Miles, M. B., \& Huberman, A. M.(1994). Qualitative data analysis: An expanded sourcebook (2nd ed.). Thousand Oaks, CA: SAGE Publications.

NRF.(2013). Americans gobbled up retailers' Thanksgiving weekend deals, according to NRF. Retrieved March 23, 2014, from https:/www.nrf.com/modules. php?name $=$ News\&op=viewlive\&sp_id $=1705$

NRF.(2014a). Holiday retail sales. Retrieved March 15, 2014, from http://research.nrffoundation.com/ Default.aspx?pg=55\#.UyPS-rfNuUk

NRF.(2014b). Holiday retail sales come in at NRF expectations. Retrieved March 15, 2014, from http://research.nrffoundation.com/Default.aspx?p $\mathrm{g}=55 \# . U y P R Y b f N u U k$

Park, S.(2014). Lotte department store's 'Black Friday' on 14th. Kyeongin Ilbo. Retrieved April 22, 2014, from http://www.kyeongin.com/news/articleView. html?idxno=815673

Puccinelli, N. M., Goodstein, R. C., Grewal, D., Price,
R., Raghubir, P., \& Stewart, D.(2009). Customer experience management in retailing: Understanding the buying process. Journal of Retailing, 85(1), 15-30.

Shim, S. I., Jang, S., \& Lee, Y.(2008). Effects of product and situation on internet browsing behavior for fashion products. Journal of Korean Society of Clothing and Textiles, 32(7), 1046-1055.

Simpson, L., Taylor, L., Kathleen, O'Rourke, \& Shaw, K.(2011). An analysis of consumer behavior on Black Friday. American International Journal of Contemporary Research, 1(1), 1-5.

Swilley, E., \& Goldsmith, R. E.(2013). Black Friday and cyber monday: Understanding consumer intentions on two major shopping days. Journal of Retailing and Consumer Services, 20(1), 43-50.

Verhagen, T., \& van Dolen, W.(2011). The influence of online store beliefs on consumer online impulse buying: A model and empirical application. Information \& Management, 48(8), 320-327.

Wang, Y. J., Minor, M. S., \& Wei, J.(2011). Aesthetics and the online shopping environment: Understanding consumer responses. Journal of Retailing, 87(1), 46-58.

Yu, Y.(2013). 'Korean version of Black Friday' Lotte department store makes two hundred million sales just after two hours from the beginning of the promotional event. Chosun Biz. Retrieved April 22, 2014, from http://biz.chosun.com/site/ data/html_dir/2013/12/04/2013120401504.html 